\title{
Passive Millimeter-wave Signatures of Ice Particles in Hurricane Erin
}

\author{
Gail Skofronick Jackson \\ Instrumentation Sciences Branch \\ NASA Goddard Space Flight Center \\ Greenbelt, MD USA \\ gailsjackson@ieee.org
}

Eric Holthaus, University of Oklahoma, and Cerese Albers, Florida State University

\begin{abstract}
Observations of Hurricane Erin (2001) taken during the Fourth Convection and Moisture Experiment (CAMEX-4) are used to elucidate relationships between measurements and models. Measurements include active and passive microwave sensors, and dropsondes. Models used in the analysis include radiative transfer (RT) models, mesoscale models (MM5), and particle parameterizations. Various combinations of the models and observational constraints are used in the RT model to provide calculated brightness temperatures to compare to the passive observations. In order to match the wide frequency range 10 to $183 \pm 10 \mathrm{GHz}$, model modifications were needed. The $\mathbf{5 5 . 5}$ $\mathrm{GHz}$ channel provided insight to the tropospheric temperature profile, while the $10 \mathrm{GHz}$ channel provided knowledge of (near) ocean surface conditions. The channels less than $\sim 90 \mathrm{GHz}$ are mostly responsive to liquid in the cloud, while higher frequencies respond to ice particles in the cloud.
\end{abstract}

Keywords-ice clouds, precipitation, millimeter-wave, retrievals.

\section{INTRODUCTION}

The development and strength of tropical cyclones is highly influenced by ice particles in hurricane rain bands and convection [1]. However, little information is known about frozen droplet characteristics in hurricane clouds. Knowledge about the size, number concentrations, and densities of frozen particles in tropical cyclones would enhance cloud resolving models. The sensitivity of higher frequency channels ( $>$ $100 \mathrm{GHz}$ ) to frozen particles has been reported in the literature [2]. Without these higher frequencies the relationships between wide-band radiometer observations and the physical and electromagnetic properties of frozen hydrometeors cannot be ascertained. The Fourth Convection and Moisture Experiment (CAMEX-4) held August-September 2001 and based from Jacksonville, FL USA provides a valuable database of active, passive, and in situ observations that can be used to investigate the relationships between frozen particles and their radiative signatures. In this work, brightness temperatures were computed and compared with observations of Hurricane Erin from CAMEX-4 radiometers on the ER-2 aircraft. These wideband observations ranged from 10.7 to $183 \pm 10 \mathrm{GHz}$. In order to initialize the cloud profiles used in the radiative transfer calculations, radar reflectivities from an
ER-2 instrument were converted to mass contents at specified height levels. Dropsonde data from the ER-2 and modeled Hurricane Erin data were used to generate profiles of temperature, pressure, and relative humidity and to provide surface wind speed and ocean temperature.

Section II describes the Hurricane Erin case study, including observations and models. Section III identifies the comparisons between various models and inputs used in the radiative transfer (RT) analysis. Section IV, that describes the radiative transfer calculations, shows that several frequencies provided focused insight into the specifics of the physical processes. Section V provides a summary and conclusions.

\section{HURRICANE ERIN CASE STUDY}

The CAMEX-4 field campaign was based in Jacksonville, Florida during August and September of 2001. This field campaign was a joint NASA and NOAA Hurricane Research Division project with the goal of studying tropical hurricane development, tracking, intensification, and land falling impacts. While CAMEX-4 had broad-based instrumentation on multiple platforms including several aircraft and ground locations, this work focuses on the observations from four instruments on the ER-2 aircraft. On board the ER-2, flying at an altitude of approximately $20 \mathrm{~km}$, the instruments of interest for this work are the High Altitude Monolithic Microwave Integrated Circuit (MMIC) Scanning Radiometer (HAMSR) [3], the Advanced Microwave Precipitation Radiometer (AMPR) [4], the ER-2 Doppler Radar (EDOP) [5], and the ER-2 dropsonde system [6]. The first three instruments measure atmospheric hydrometeors in the microwave region of the electromagnetic spectrum, while the dropsondes are released from the ER-2 and measure temperature, relative humidity and wind speed as they fall toward the Earth's surface. The HAMSR has 8 observations between 50 and $57 \mathrm{GHz}$, plus 166, 183.3 \pm 1 , $183.3 \pm 1.8,183.3 \pm 3,183.3 \pm 4.5,183.3 \pm 7$, and $183.3 \pm 10 \mathrm{GHz}$ while the AMPR observes at the lower frequencies of 10.7 , 19.35, 37, and $85.5 \mathrm{GHz}$. The EDOP is an active radar sampling at $9.6 \mathrm{GHz}$ with a range gate interval of 37.5 meters.

The focus is on the rain bands and anvil regions associated with Hurricane Erin, located in the Atlantic Ocean. Hurricane Erin was weakening from a peak category 3 storm on 10 Sept 


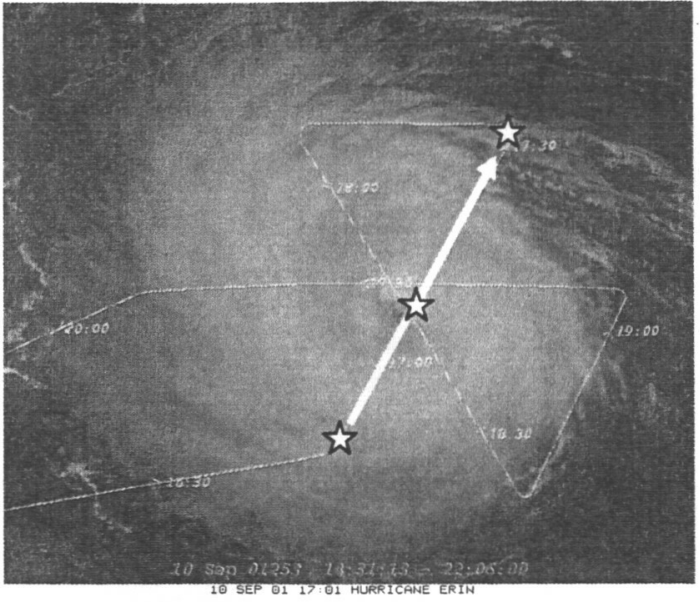

Figure 1. Visible GOES image with 10 September 2001 ER-2 aircraft flight track superimposed. The flight line analyzed herein is indicated with a thick white line. Stars indicate dropsonde release locations.

2001. The GOES satellite image is provided in Fig. 1 with the ER-2 aircraft flight line superimposed on top of it. The flight line begins at $33.9 \mathrm{~N}, 66.14 \mathrm{~W}$ and goes to $37.22 \mathrm{~N}, 63.64 \mathrm{~W}$ in a straight track. Only the nadir or near-nadir signatures are used in this work.

The data sets from the MIR, HAMSR, and EDOP have been analyzed and collocated with about a $2.5 \mathrm{~km}$ footprint resolution. Figure 2 shows the EDOP, HAMSR, and AMPR observed data for Hurricane Erin on 10 September 2001 between 16:49:59 UTC and 17:25:00 UTC, including EDOP data (upper panel), selected HAMSR brightness temperatures (TB) (two center panels), and AMPR TB (lower panel). For this image, the ER-2 is flying toward the northeast as indicated in Fig. 1. In the image the hurricane eye is surrounded by several rain bands with anvil, convective, and stratiform regions. From Fig. 2, it can be discerned that the higher frequencies of the HAMSR data $(\geq 166 \mathrm{GHz})$ are sensitive to the frozen particles in the cloud (as indicated by non-zero reflectivities above the melting layer in the EDOP image collocated with depressions in the TB at 166 and $183 \mathrm{GHz}$ ). On the other hand, the AMPR lower frequency channels are sensitive to the liquid in the rain bands. Although not readily apparent in Fig. 2, the HAMSR 50-60 GHz channels are mostly sensitive to the temperature profile.

\section{MODELS AND INPUTS}

For physically-based analysis of the AMPR and HAMSR passive observations, a cloud profile data set must be generated for use in RT calculations. The radar reflectivity can provide some information about the vertical hydrometeor contents, however additional data about the profile and boundary conditions are also required. Essentially there are three steps: (1) the radar reflectivities need to be converted into vertical hydrometeor content profiles, (2) the temperature, pressure, and relative humidity information needs to be incorporated into the vertical profiles, and (3) the ocean surface wind speed and temperature must be assigned. To obtain information for steps 2 and 3, dropsonde and hurricane model data is used.
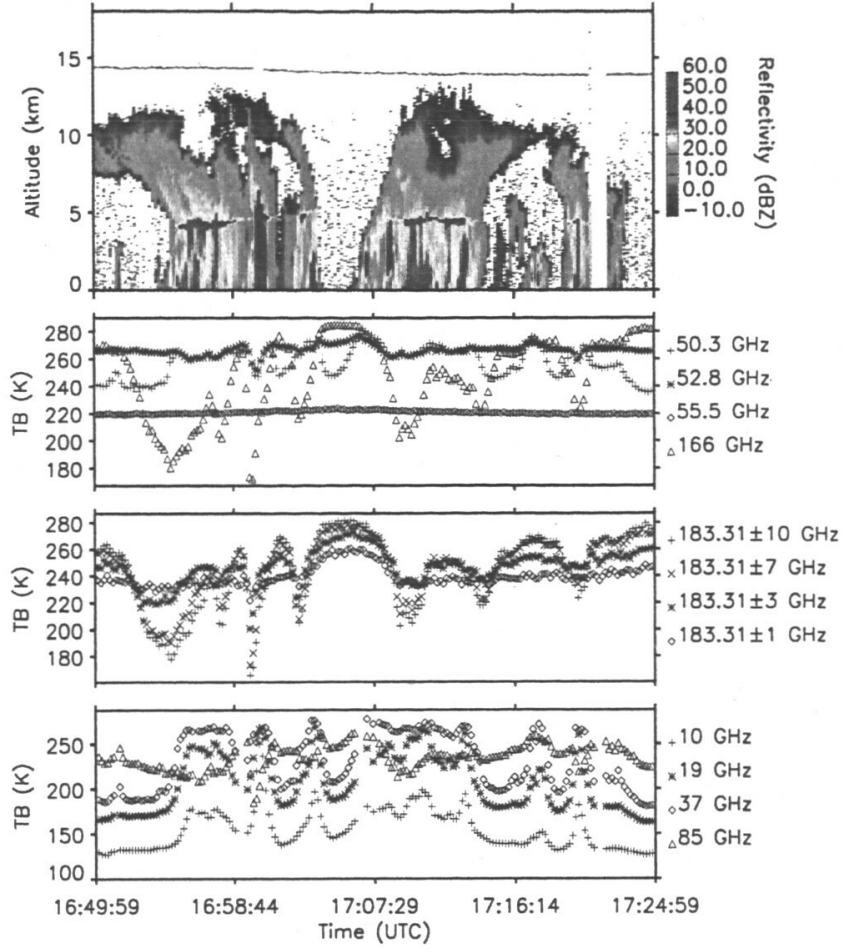

Figure 2. Observations of Hurricane Erin. Upper Panel: EDOP reflectivities, Middle Panels: HAMSR brightness temperatures, Lower Panel: AMPR brightness temperatures.

For step 1, attenuation corrected [7] nadir-viewed radar reflectivity profiles are converted into estimates of hydrometeor content profiles. The fine $(37.5 \mathrm{~m})$ resolution of the radar range gates from 0 to $\sim 18 \mathrm{~km}$ is averaged to a 0.25 $\mathrm{km}$ resolution. The hydrometeor content profiles from the radar-to-microphysical profile algorithm are partitioned into liquid and frozen particles with Marshall-Palmer [8] and Sehkon-Srivastava [9] exponential drop size distributions, respectively. While continuity of the precipitation flux across the freezing level is not explicitly enforced, the masses obtained from the radar reflectivities should have smooth transitions from one level to the next. In this work, $\mathrm{Z}$ refers to the reflectivity of the calculations and to the attenuationcorrected $Z_{m}$ for the observations.

The second step involves obtaining appropriate temperature $(\mathrm{T})$, pressure $(\mathrm{P})$, and relative humidity $(\mathrm{RH})$ profiles. Despite the historic data collection efforts of the CAMEX-4 experiment, which included the first stratospheric in-situ sampling [6] of a mature tropical cyclone, there remained significant gaps in the dropsonde data, with only three dropsondes released along the selected $430 \mathrm{~km}$ flight path. (See star symbols on Fig. 1 for dropsonde releases at 16:47:56 UTC, 17:04:27 UTC, and 17:31:05 UTC.) Note that other dropsondes were released elsewhere. With limited in situ data, the available Mesoscale Model-5 (MM5) simulations of Hurricane Erin [10] were used. This modeled data was developed with a resolution of $2.0 \mathrm{~km}$ horizontally and ranges between 0.004 and $1.0 \mathrm{~km}$ vertically. In order to extract appropriate T, P, and RH profiles, the MM5 computed reflectivity profiles were compared to each 
of the EDOP reflectivity profiles. The T, P, and RH of the 5 MM5 profiles closest to each EDOP reflectivity profile were averaged to generate the needed $\mathrm{T}, \mathrm{P}$, and $\mathrm{RH}$ data.

The third and final step is to insert surface boundary conditions. For the boundary conditions at the top of the profile, the maximum height level is $18 \mathrm{~km}$ near the ER-2 flight altitude. Radiation from the cosmic background is incorporated in the radiative transfer calculations so that the effects of scattering from the ice at the top of the clouds are included. For the surface conditions, an oceanic surface is assumed since the flight leg is over ocean during the focus times. The ocean surface temperature is obtained from the Hurricane Erin simulations for the 5-profile averages as discussed above for the RH and T profiles. For the surface wind speed, the MM5 Hurricane Erin simulations were analyzed to find a horizontal cut in the storm with a surface wind speed pattern as would be expected by the EDOP image in terms of eyewall locations and convective regions.

\section{Radiative Transfer Calculations}

The RT equations rely on the planar-stratified, scattering based model described in [11]. Calculations were performed over the ocean where surface emissivity could be computed using Fresnel coefficients. The input for the radiative transfer code was provided in the previous section, where the atmospheric and hydrometeor profiles were specified using a combination of MM5 simulated data and ER-2 dropsonde data. The liquid particles are assumed to have a Marshall-Palmer particle size distribution (PSD), while here the frozen drops have a Sehkon-Shrivastava PSD.

The $55.5 \mathrm{GHz}$ channel of HAMSR is sensitive to the top of atmosphere temperature profile as can be seen in Fig. 3 where the solid black lines of the observations are smooth and show no effects of the upper altitude ice profiles. The dotted red line shows the computed brightness temperatures (TB) using the MM5 Hurricane Erin simulation data. It is clear that the MM5 simulations have slightly too warm upper altitude temperature profiles. This is likely attributable to the coarser vertical resolution for MM5 profiles above $300 \mathrm{mb}$ [10]. When the MM5 temperature profiles are allowed to transition to an average (16:47:56 and 17:31:05 UTC) dropsonde profile between 6.5 and $7.5 \mathrm{~km}$, the result is shown with the dotdashed blue line in Fig. 2. The 17:04 UTC dropsonde is not used in the average because it increases the computed 55.5 $\mathrm{GHz}$ TB by about $2.5 \mathrm{~K}$. (The problems with the 17:04 UTC dropsonde may be due to the $0.25 \mathrm{~km}$ vertical averaging method.) Not explored is the possibility that the dropsonde temperature profiles are too warm by about $1 \mathrm{~K}$ (See http://eis.jpl.nasa.gov/mtp/missions/camex4/Science/CAMEX4 Temperature Comparisons.html) If true, the $55.5 \mathrm{GHz} \mathrm{TB}$ calculations outside the eye may match the $55.5 \mathrm{GHz}$ observations better. The problems in getting the calculations of $55.5 \mathrm{GHz}$ to match the observations indicate a disconnect between models and observations.

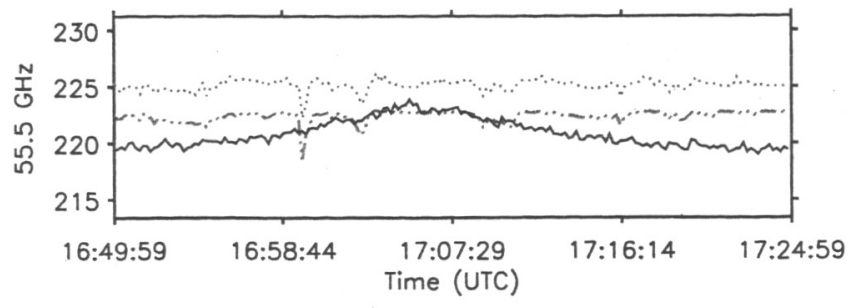

Figure 3. The $55.5 \mathrm{GHz}$ observations (solid-black line)compared to two calculated cases, where red (dotted) line is for the MM5 Hurricane Erin simulation and the blue (dash-dotted) line is for MM5 from 0 to $7 \mathrm{~km}$ and dropsonde data from 7 to $18 \mathrm{~km}$.

The $10 \mathrm{GHz}$ channel is primarily sensitive to the surface conditions when no precipitation is present. Fig. 4 shows the $10 \mathrm{GHz}$ channel observations (black solid line) along with the averaged Hurricane Erin simulations (red dotted line). In the eye the MM5 simulations are too cold. It is possible that the ocean surface has wind generated foam that has not yet dissipated from the eyewall passing. When the wind speed is artificially increased to $30 \mathrm{~m} \mathrm{~s}^{-1}$ in the eye, the results are shown by the dot-dashed blue line in Fig 4. This is a better fit for the eye, but lacking in that the transition is abrupt. It is also possible that the EDOP does not register high water vapor in the eye. A case with increased water vapor near the surface was tested. The results for a high water vapor are shown in green (dashed line) on Fig. 4. As a final test, the T, P, RH from the 17:04 UTC dropsonde was used from 0 to $7.5 \mathrm{~km}$ and then a transition to the averaged dropsonde was performed (turquoise line). This last test was designed because the MM5 simulations have a minimum surface pressure of $971 \mathrm{mb}$. The eye dropsonde shows that the minimum surface pressure is closer to $940-950 \mathrm{mb}$. It can be seen that only the changes in wind speed affect the $10 \mathrm{GHz}$ channel in the rain-free eye region.

A further comparison at $89,183 \pm 1$, and $183 \pm 10 \mathrm{GHz}$ was performed. In this comparison, the frozen particles were allowed to have the Sehkon-Srivastava PSD or to have a large, fluffy, low density (10\% ice) PSD. As can be seen in Fig 5 , the fluffy particles generate TB values that are too warm because the scattering and asymmetry parameters do not generate the right amount and direction of scattering. However the SehkonSrivastava PSD generates too cool TB values for similar reasons. More information about the influence of PSD on TB calculations can be found in [2].
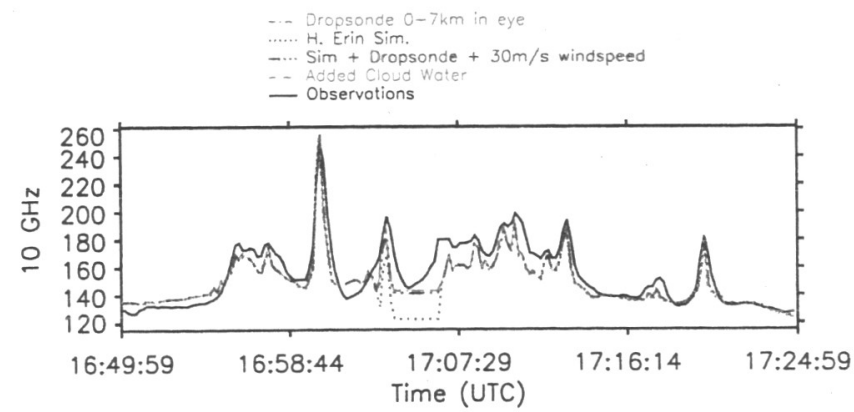

Figure 4. The $10 \mathrm{GHz}$ observations compared to four calculated cases. 

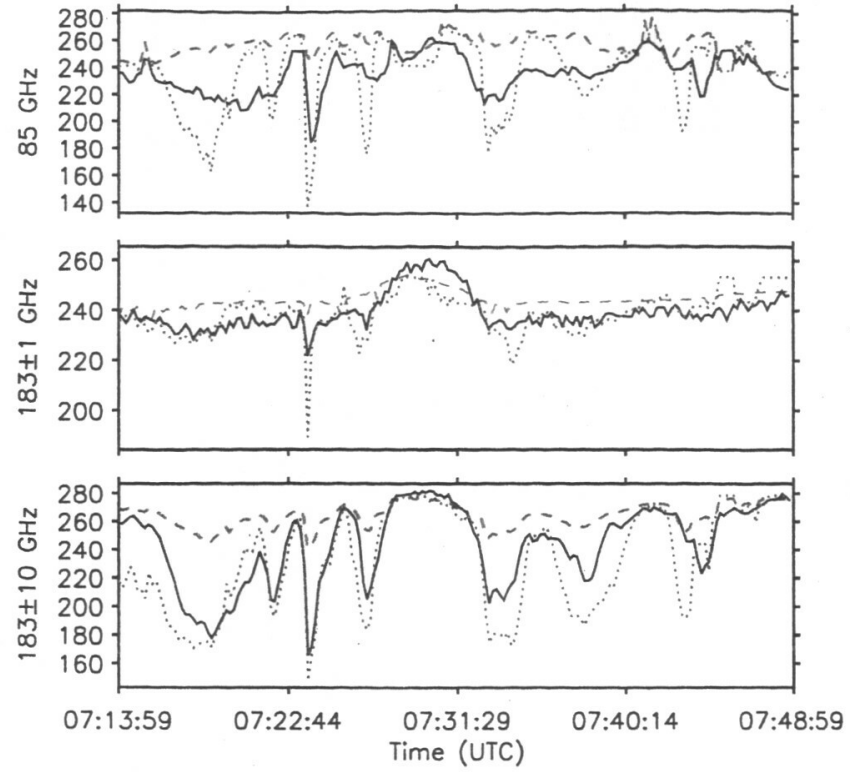

Figure 5. Comparisons between observations and frozen particles with a Sekhon-Srivastava PSD (read dotted line) and dry, low-density, large fluffy PSD (blue dashed line).

\section{SUMMARY AND CONCLUSIONS}

This paper has shown that there is a disconnect between brightness temperature observations, cloud resolving model simulations (MM5), and dropsonde measurements. The paper also shows that the high frequencies are sensitive to the way ice particles are modeled electromagnetically. While ice particle electromagnetic (radiative) models are undergoing significant innovations [12], additional global observations at higher frequencies will provide data useful for further understanding the ice processes in clouds.

\section{ACKNOWLEDGMENTS}

Al Gasiewski is thanked for providing the radiative transfer code many years ago, Scott Braun is thanked for generating and providing the MM5 model simulation, while Gerry
Heymsfield, Bjorn Lambrightsen, and Jeff Halverson are thanked for providing EDOP, HAMSR, and dropsonde data respectively. This work was supported by Ramesh Kakar at NASA Headquarters through CAMEX-4 funding.

\section{REFERENCES}

[1] Willoughby, H.E., 1998: Tropical cyclone eye thermodynamics. Mon. Wea. Rev., 126, 3053-3067.

[2] Skofronick-Jackson, G. M., A. J. Gasiewski, and J. R. Wang,, "Influence of Microphysical Cloud Parameterizations on Microwave Brightness Temperatures," IEEE Trans. Geosci. and Remote Sensing, vol. 40, pp. 187-196, 2002.

[3] Lambrigtsen, B. H. and A. L. Riley, 2002: Microwave Scattering Observed in Convective Cells During CAMEX-4. Proceedings AMS 25 th Conference on Hurricanes and Tropical Meteorology; San Diego, CA, 13A.6.

[4] Spencer, R.W., R.E. Hood, F.J. LaFontaine, E.A. Smith, R. Platt, J. Galliano, V.L. Griffin, and E. Lobl, 1994: High-resolution imaging of rain systems with the advanced microwave precipitation radiometer. $J$. Atmos. Ocean. Tech., 11, 849-857.

[5] Heymsfield, G. M., S. Bidwell, I. J. Caylor, S. Ameen, S. Nicholson, W. Boncyk, L. Miller, D. Vandemark, P. E. Racette, and L. R. Dod, 1996: The EDOP radar system on the high-altitude NASA ER-2 aircraft. $J$. Atmos. Ocean. Tech., 13, 795-809.

[6] Halverson, J.B., J. Simpson, G. Heymsfield, H. Pierce, T. Hock, and L. Ritchie, 2004: Warm core structure of Hurricane Erin diagnosed from high altitude dropsondes during CAMEX-4. J. Atmos. Sci., submitted to CAMEX4 special issue 2005.

[7] Hitschfeld, W. and J. Bordan, 1954: Errors inherent in the radar measurement of rainfall at attenuating wavelengths. J. Meteor., 11, 5867.

[8] Marshall, J. S. and W. M. Palmer, 1948: The distribution of raindrops with size, J. Meteor., 5, 165-166.

[9] Sehkon, R. S. and R. Srivastava, 1970: Snow size spectra and radar reflectivity, J. Atmos. Sci., 27, 299-307.

[10] Wu, L, S. A. Braun, J. Halverson, and G. Heymsfield, "A Numerical Study of Hurricane Erin (2001). Part I: Model Verification and Storm Evolution", J. Atmos. Sci., submitted to CAMEX4 special issue 2005.

[11] Gasiewski, A. J., 1993: Microwave radiative transfer in hydrometeors. Atmospheric Remote Sensing by Microwave Radiometry, M. A. Janssen, Ed. John Wiley and Sons, 91-144.

[12] Kim, M.-J., and J. A. Weinman, "Computation of Electromagnetic Characteristics of Frozen Hydrometeors at Millimeter-wave Frequencies," IGARSS 2005, Anchorage Alaska. 